\title{
Antibiotic-Resistant Bacteria Are Major Threats of Otitis Media in Wollo Area, Northeastern Ethiopia: A Ten-Year Retrospective Analysis
}

\author{
Ayele Argaw-Denboba, ${ }^{1}$ Asrat Agalu Abejew, ${ }^{2}$ and Alemayehu Gashaw Mekonnen ${ }^{3}$ \\ ${ }^{1}$ Department of Experimental Medicine and Surgery, University of Rome Tor Vergata, Via Montpellier 1, 00133 Rome, Italy \\ ${ }^{2}$ Department of Pharmacy, College of Medicine and Health Sciences, Wollo University, P.O. Box 1145, Dessie, Ethiopia \\ ${ }^{3}$ Microbiology Unit, Dessie Regional Health Research Laboratory, P.O. Box 686, Dessie, Ethiopia \\ Correspondence should be addressed to Ayele Argaw-Denboba; aye7898@yahoo.com
}

Received 20 August 2015; Revised 17 November 2015; Accepted 24 December 2015

Academic Editor: Liang-Chun Liu

Copyright (c) 2016 Ayele Argaw-Denboba et al. This is an open access article distributed under the Creative Commons Attribution License, which permits unrestricted use, distribution, and reproduction in any medium, provided the original work is properly cited.

\begin{abstract}
Antibiotic resistance is an increasingly serious threat to human health that needs an urgent action. The aim of this study was to determine the prevalence and antibiotic susceptibility profiles of bacteria isolated from patient ear discharges suspected of otitis media. A retrospective analysis was performed using culture and antibiotic susceptibility test results of 1225 patients who visited Dessie Regional Health Research Laboratory from 2001 to 2011. Results showed a strong association $(P<0.001)$ between age and the risk of acquiring middle ear infection. The predominant bacterial isolates were Proteus spp. (28.8\%), Staphylococcus aureus (23.7\%), and Pseudomonas spp. (17.2\%). Most of the isolated bacteria showed high resistance to ampicillin (88.5\%), ceftriaxone (84.5\%), amoxicillin (81.9\%), and tetracycline (74.5\%). About $72.5 \%$ of Proteus spp. and $62.2 \%$ of Pseudomonas spp. have developed resistance to one and more antibiotics used to treat them. This retrospective study also revealed the overall antibiotic resistance rate of bacterial isolates was increased nearly twofold $(P=0.001)$ over the last decade. Relatively, ciprofloxacin and gentamicin were the most effective antibiotics against all the isolates. In conclusion, antibiotic-resistant bacteria are alarmingly increasing in Wollo area, northeastern Ethiopia, and becoming a major public health problem in the management of patients with middle ear infection.
\end{abstract}

\section{Introduction}

Ear infection is a common clinical problem throughout the world and the major cause of preventable hearing loss in the developing world $[1,2]$. Microbial agents can infect the middle and external parts of the ear and may involve the skin, cartilage, periosteum, ear canal, and tympanic and mastoid cavities [3]. Ear infection can be classified as acute suppurative otitis media (ASOM), chronic suppurative otitis media (CSOM), or otitis externa (OE) [4]. Its chronic form is a serious problem in all age groups with less chance of recovery. In certain cases this condition can lead to serious life-threatening complications, such as hearing impairment, brain abscesses, or meningitis, mostly in childhood and late in life $[2,4]$. According to the World Health Organization
(WHO) estimates of 2015 over $5 \%$ of the world's populations (328 million adults and 32 million children) have disabling hearing loss. The highest prevalence is found in the AsiaPacific, South Asia, and Sub-Saharan African regions. Half of all cases of hearing loss are avoidable through primary prevention while many can be treated. A leading cause of hearing loss in younger ages, particularly in low- and middle-income countries, is untreated ear infections, often with discharge from the ear. Vaccine-preventable infectious diseases such as rubella, meningitis, measles, or mumps can also lead to hearing loss $[2,4]$.

The causative agents of ear infection might be bacterial, viral, or fungal. However, the major causative agents of ear infection are bacterial isolates such as Pseudomonas aeruginosa, Escherichia coli, S. aureus, Streptococcus pyogenes, 
Proteus mirabilis, Klebsiella spp., or mixed bacterial infection [5]. The microbiological profiles of ear infection are well documented in developed world. However, so far few studies have been conducted in most developing countries [610]. Moreover, the signs and symptoms of earache may often mislead the etiology of the infection, which makes it very difficult for the clinician to relate the disease to the exact etiology. Hence, the physician may advocate antibiotic therapy irrespective of the etiology of the disease. This may lead to unwanted economic loss, stress to the patient if the ear infection is due to the virus or fungi, and foremost antibiotic resistance [11]. For these reasons, it is very important to study the microbiological profiles of ear infection and their extent of antibiotic resistance in those developing countries for the proper management of patients with ear infections. Moreover, antibiotic resistance is a growing global problem listed among major threats to human health by the World Health Organization [10].

Ethiopia is among the least developing countries and there are only a handful of studies reported so far that showed the prevalence and antibiotic resistance profile of bacterial isolates associated with ear infections [12-19]. Therefore, in this study, we showed a ten-year retrospective analysis of culture and antibiotic susceptibility test results of middle ear discharge from patients suspected of having a middle ear infection and referred to Dessie Regional Health Research Laboratory (DRHRL), located in Dessie town, northeastern Ethiopia.

\section{Methods}

2.1. Study Design, Site, and Data Collection. This retrospective study was conducted from June 1 to August 31, 2012. During this period we reviewed culture and antibiotic susceptibility test results of middle ear discharges from 1225 patients suspected of middle ear bacterial infection and referred to DRHRL from September 2001 to September 2011 for antimicrobial sensitive test. DRHRL is located in Dessie town, South Wollo Zone, northeastern Ethiopia. This health research laboratory is the only regional referral laboratory found in the northeastern parts in Ethiopia serving populations of more than 4 million surrounding it [20]. Patient data were collected by the principal investigators using retrospective chart review data collection method based on the articulated aims of this study. Thus, all patient information registered in microbiology laboratory unit patient registration books from September 2001 to September 2011 were collected, including patient sociodemographic characteristics, isolated bacteria from middle ear discharge, and their antibiotic susceptibility test results categorized in each year of the study period. Of note, data with incomplete records or illegible handwriting were excluded from this study.

2.2. Laboratory Diagnostic Methods. As the standard operational procedure of DRHRL microbiology unit shows, ear discharge specimens were taken aseptically using sterilized cotton swabs from each patient; then specimens were inoculated on MacConkey agar, blood agar, mannitol salt agar, and chocolate agar plates using sterilized $0.001 \mathrm{~mL}$ inoculation loop (all media from Oxoid Limited, UK). The plates of MacConkey, blood, and mannitol salt agar were placed in an aerobic incubator while the chocolate plate was incubated in a carbon-dioxide enriched atmosphere at $37^{\circ} \mathrm{C}$ for 24 hours. The swarming feature of Proteus spp. was managed by subculturing mixed colonies into MacConkey agar that has bile salt and by adding $5 \%$ of $90 \%$ ethanol. Bacterial isolation and identification were performed according to standard microbiological methods as described in the notable book of Monica Cheesbrough [21]. In brief, Gram-negative bacteria were identified by performing a series of biochemical tests, namely, triple sugar iron agar, indole, Simon's citrate agar, lysine iron agar, urea, mannitol, and motility. Gram-positive bacteria were identified based on their Gram reaction, novobiocin, catalase, and coagulase test results.

Antimicrobial susceptibility tests were performed on Mueller-Hinton agar (Oxoid Limited, UK) using modified Kirby-Bauer disc diffusion method [22]. The susceptibility pattern of each bacterial isolate was interpreted according to the standard criteria of Clinical and Laboratory Standards Institute (CLSI, 2011). The antimicrobial agents tested were amoxicillin $(10 \mu \mathrm{g})$, tetracycline $(30 \mu \mathrm{g})$, TMP-SMX $(25 \mu \mathrm{g})$, cephalothin $(30 \mu \mathrm{g})$, ampicillin $(10 \mu \mathrm{g})$, chloramphenicol $(30 \mu \mathrm{g})$, ceftriaxone $(30 \mu \mathrm{g})$, ciprofloxacin $(5 \mu \mathrm{g})$, doxycycline $(30 \mu \mathrm{g})$, erythromycin $(15 \mu \mathrm{g})$, gentamicin $(10 \mu \mathrm{g})$, cefotaxime $(30 \mu \mathrm{g})$, kanamycin $(30 \mu \mathrm{g})$, nitrofurantoin $(300 \mu \mathrm{g})$, vancomycin $(30 \mu \mathrm{g})$, carbenicillin $(100 \mu \mathrm{g})$, and clindamycin $(2 \mu \mathrm{g})$ (Oxoid Limited, UK). To assure the accuracy and reliability of antimicrobial susceptibility test, the reference strains S. aureus (ATCC25923), Escherichia coli (ATCC25922), and $P$. aeruginosa (ATCC 27853) were used as internal quality controls.

2.3. Statistical Analysis. Data were checked for completeness, cleaned manually, entered, and analyzed using SPSS version 20 statistical software and Excel. The chi-square test $\left(\chi^{2}\right)$ was used to measure the association between sex and age with susceptibility to middle ear infection and paired Student's $t$-test was applied to compare antimicrobial resistance rates between the start and end of the study period. The $P$ value of $<0.05$ was considered to show a statistically significant difference.

2.4. Ethical Considerations. Ethical clearance was obtained from Ethical Review Committee of Wollo University. A formal supportive letter was also obtained from the Wollo University to the head of Dessie Regional Health Research Laboratory for cooperation and permission to get the tenyear data record. Patient privacy was protected by deidentification of records. Names of patients were replaced by initials. All data obtained in the course of the study were kept confidential and used only for this study.

\section{Results}

3.1. Age and Sex Distribution of Patients Suspected of Otitis Media. After the analysis of 1225 ear discharge culture results of suspected patients, about 1024 (83.6\%) were found positive for one or more bacterial species. The result displayed in 
TABLE 1: Age and sex distribution of bacteria positive middle ear discharges diagnosed from 2001 to 2011 in Dessie Regional Laboratory $(n=1024)$.

\begin{tabular}{lcc}
\hline Variables & Frequency of bacteria positive ear discharges Number (\%) & $\chi^{2}$ \\
\hline Sex & & $P$ value \\
Men & $516(50.4)$ \\
Women & $503(49.1)$ & 45 \\
$\quad$ Unspecified & $5(0.5)$ & \\
Age group in years & $153(14.9)$ & \\
$\quad<5$ & $253(24.7)$ \\
$5-15$ & $434(42.4)$ \\
$16-35$ & $105(10.3)$ \\
$36-50$ & $47(4.6)$ \\
$\geq 51$ & $32(3.1)$ & \\
Unspecified & & \\
\hline$\chi^{2}:$ chi-square test; $P<0.001$ implies in each year of the study period "age" has a significant influence on developing bacterial middle ear infection.
\end{tabular}

TABLE 2: Ten-year retrospective analysis of bacterial isolates from ear discharges.

\begin{tabular}{lcc}
\hline Bacteria isolated & Frequency & Percentage (\%) \\
\hline Proteus spp. & 324 & 28.8 \\
S. aureus & 266 & 23.7 \\
Pseudomonas spp. & 193 & 17.2 \\
E. coli & 184 & 16.4 \\
Citrobacter spp. & 66 & 5.9 \\
Enterobacter spp. & 53 & 4.7 \\
Klebsiella spp. & 32 & 2.8 \\
S. epidermidis & 5 & 0.4 \\
S. pneumoniae & 1 & 0.1 \\
\hline Total & $\mathbf{1 1 2 4}$ & $\mathbf{1 0 0}$ \\
\hline
\end{tabular}

Table 1 shows both men and women were at equal risk of acquiring middle ear infection by $50.4 \%$ and $49.1 \%$, respectively. The frequency of positive ear discharge cultures was higher in the age group of $16-35$ years $(42.4 \%)$ followed by the age group $5-15$ years $(24.7 \%)$ (Table 1$)$. The chi-square test showed age and frequency of bacterial positive ear discharge in each year of the study period were strongly associated $(P<0.001)$.

3.2. Prevalence of Isolated Bacteria from Ear Discharges. Out of 1024 bacteria positive patient ear discharge specimens' 9 different pathogenic bacteria species were identified. Among these bacterial species, the predominant bacterial isolate was Proteus spp. 324 (28.8\%) followed by S. aureus 266 (23.7\%) and Pseudomonas spp. 193 (17.2\%) (Table 2).

3.3. Overall Antibiotic Susceptibility Profiles of Isolated Bacteria from Ear Discharge. During the ten-year period 17 different antimicrobial agents were used to test the antibiotic susceptibility patterns of the pathogenic bacteria isolated from ear discharges. The overall susceptibility profiles of bacterial isolates are shown in Table 3. Out of the total antibiotics examined during the ten-year period, ampicillin had the highest overall resistance rate $(88.5 \%)$ followed by ceftriaxone (84.5\%), amoxicillin (81.9\%), and tetracycline (74.5\%). Conversely, majority of bacterial isolates were susceptible to ciprofloxacin, gentamicin, and nitrofurantoin with overall resistance rates of $6 \%, 17.2 \%$, and $21.5 \%$, respectively.

3.4. Species Specific Antibiotic Susceptibility Profile of Pathogenic Bacteria Isolated from Ear Discharges. Species specific antibiotic susceptibility profiles are displayed in Table 4. Proteus spp., the most frequently isolated bacterium, showed high resistance rate $(>74 \%)$ to each of the following antibiotics: amoxicillin, tetracycline, ampicillin, chloramphenicol, ceftriaxone, doxycycline, erythromycin, cefotaxime, and vancomycin. Likewise, $S$. aureus showed a resistance rate of $(>52 \%)$ to each of the following antibiotics: amoxicillin, tetracycline, ampicillin, and cefotaxime. Pseudomonas spp., the third most common isolates, exhibited resistance rates of $(>73 \%)$ to each of the following antibiotics: amoxicillin, tetracycline, TMP-SMX, ceftriaxone, doxycycline, erythromycin, and cefotaxime. E. coli had also showed resistance rates of more than $63 \%$ for each of the following antibiotics: amoxicillin, tetracycline, ampicillin, doxycycline, and erythromycin. In contrast, almost all the isolated pathogenic bacteria were susceptible to ciprofloxacin and gentamicin with resistance rates of $0 \%-10 \%$ and $2 \%-25 \%$, respectively.

\subsection{Multi-Antibiotic-Resistant Pathogenic Bacteria Isolated} from Ear Discharges. Almost all the isolated bacteria were found to be resistant to one and more of the commonly used antibiotics (Figure 1(a)). Among the total Proteus spp. isolated, the majority (72.5\%) of the isolates have developed resistance to one and more antibiotics in clinical use. Similarly, about two-thirds of (62.2\%) Pseudomonas spp. isolates were able to resist one and more antibiotics commonly used to treat them. About $34 \%-59.9 \%$ of the other bacterial isolates have also showed overall antibiotic resistance to one and more antibiotics used in clinics. Comparing the overall antibiotic resistance rate of bacterial isolates from start to end of the study periods (2001-2 versus 2010-11) the resistance rate to one and more of the antibiotics was increased nearly twofold (34\% versus $66 \%, P=0.001$ ) (Figure $1(\mathrm{~b})$ ). 
TABLE 3: Overall antibiotic susceptibility profiles of isolated bacteria from ear discharge.

\begin{tabular}{|c|c|c|c|}
\hline \multirow[b]{2}{*}{ Type of antibiotics used } & \multirow[b]{2}{*}{ Frequency of each antibiotic tested } & \multicolumn{2}{|c|}{ Susceptibility patterns } \\
\hline & & $\begin{array}{c}\text { Resistant } \\
\text { Number (\%) }\end{array}$ & $\begin{array}{c}\text { Sensitive } \\
\text { Number (\%) }\end{array}$ \\
\hline Amoxicillin & 491 & $402(81.9)$ & $89(18.1)$ \\
\hline Tetracycline & 860 & $641(74.5)$ & $219(25.5)$ \\
\hline TMP-SMX & 684 & $367(53.6)$ & $317(46.4)$ \\
\hline Cephalothin & 213 & $96(45.1)$ & $117(54.9)$ \\
\hline Ampicillin & 106 & $94(88.5)$ & $12(11.5)$ \\
\hline Chloramphenicol & 698 & $353(50.6)$ & $345(49.4)$ \\
\hline Ceftriaxone & 1319 & $1115(84.5)$ & $204(15.5)$ \\
\hline Ciprofloxacin & 501 & $30(6)$ & $471(94)$ \\
\hline Doxycycline & 206 & $147(71.4)$ & $59(28.6)$ \\
\hline Erythromycin & 634 & $438(69.1)$ & $196(30.9)$ \\
\hline Gentamicin & 984 & $169(17.2)$ & $815(82.8)$ \\
\hline Cefotaxime & 396 & $245(61.9)$ & $151(38.1)$ \\
\hline Kanamycin & 129 & $50(38.7)$ & $79(61.3)$ \\
\hline Nitrofurantoin & 107 & $23(21.5)$ & $84(78.5)$ \\
\hline Vancomycin & 120 & $72(60)$ & $48(40)$ \\
\hline Carbenicillin & 49 & $22(44.8)$ & $27(55.2)$ \\
\hline Clindamycin & 124 & $36(29)$ & $88(71)$ \\
\hline Total & 7621 & $4299(56.4)$ & $3322(43.5)$ \\
\hline
\end{tabular}

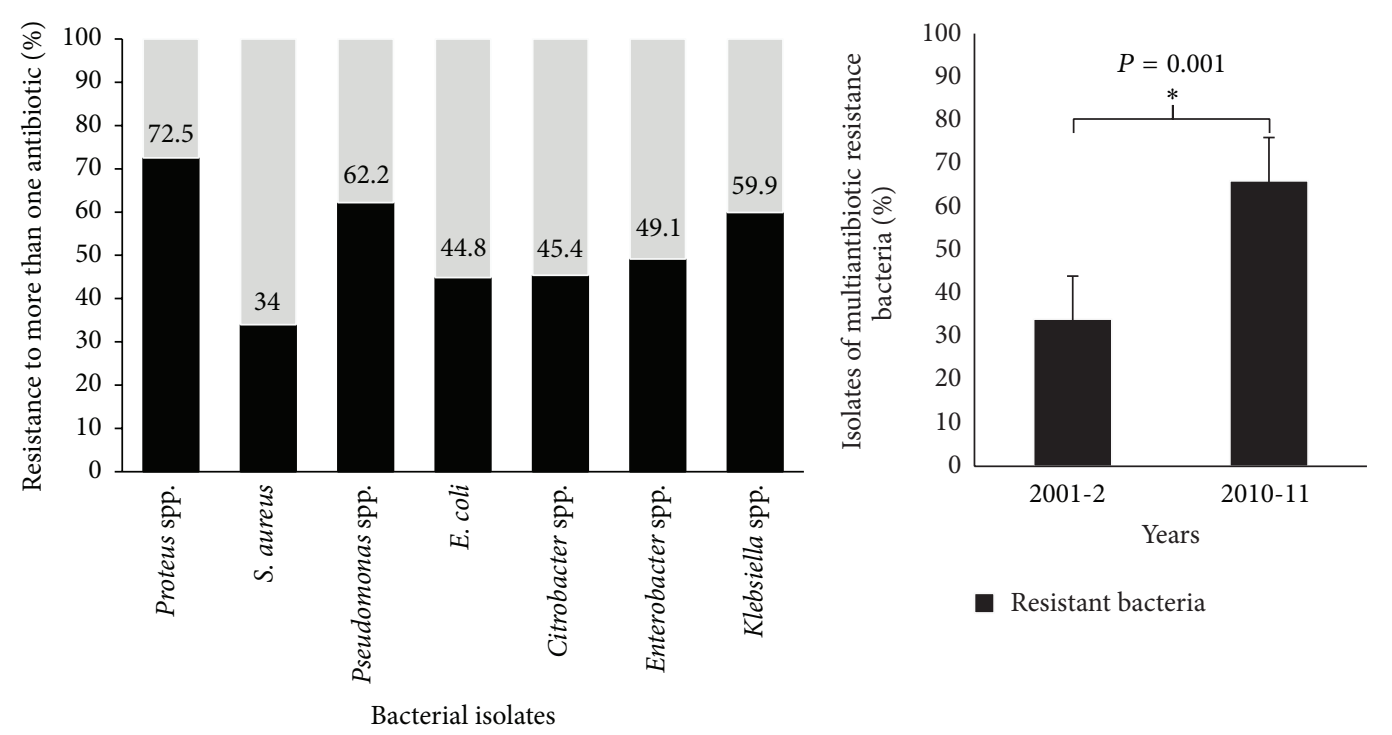

(b) Isolates of multi-antibiotic-resistant bacteria

(a) Multi-antibiotic-resistant bacteria isolated from ear discharges in Wollo area from 2001 to 2011 doubled over the periods of 2001 to 2011

FIGURE 1: Rates of multi-antibiotic-resistant pathogenic bacteria isolated from patients suspected of having otitis media.

\section{Discussion}

Ear infection is a more frequent treatable health care problem worldwide, yet if left untreated, it can cause a serious complication such as a speech development disorder, hearing loss, distress in patients and their family quality of life, and economic burden on the health care system [2]. The burden and prevalence of ear infection are more intense in developing countries due to the poor living standard and hygienic conditions along with lack of proper nutrition $[5,19$, 23]. Thus, highlighting the etiologies of ear infection and their antibiotic susceptibility pattern will help to lessen the severe 


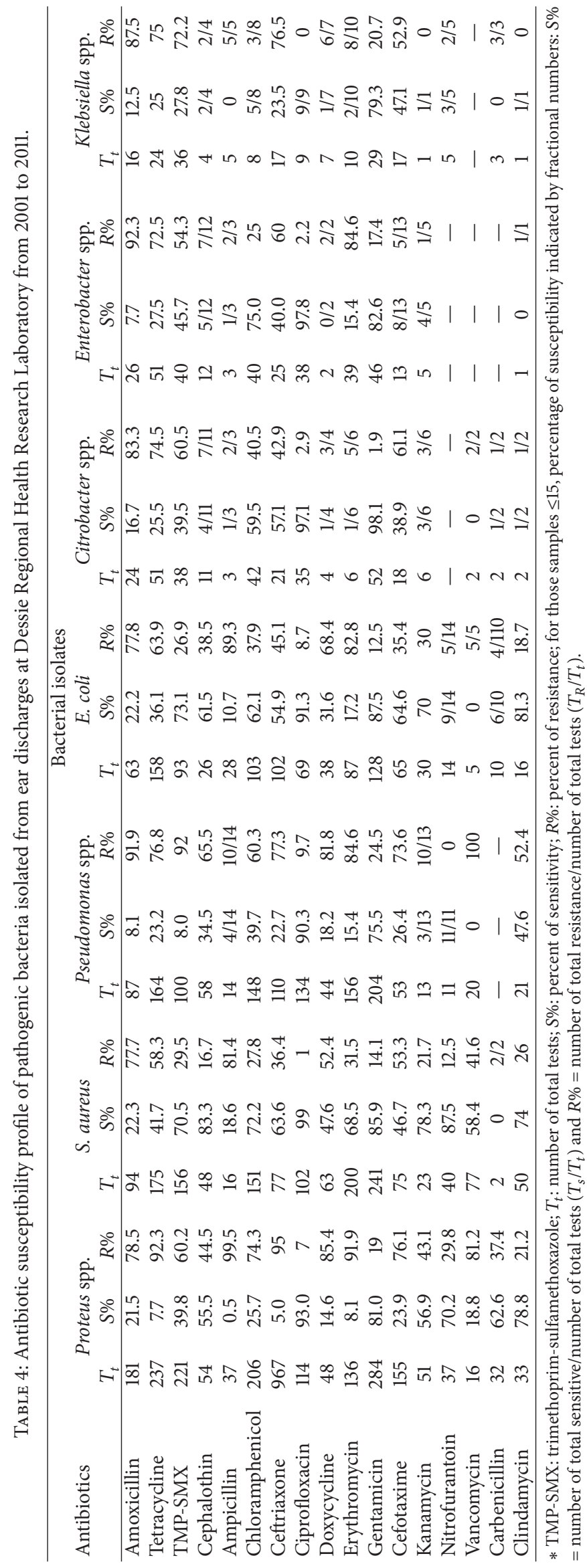


complication of the infection and guide the empirical antibiotic prescribed by the physicians, especially for developing countries $[19,24]$. On top of these issues, increased antimicrobial resistance is one of the greatest global public health challenges, which has been accelerated by overprescription of antibiotics worldwide. Infection with antibiotic-resistant bacteria may cause severe illness, increased mortality rates, and an increased risk of complications and admission to hospital and longer stay [24-26]. In light of these facts, this study revealed that Proteus spp., S. aureus, Pseudomonas spp., and $E$. coli were the most prevalent multi-antibiotic-resistant pathogenic bacteria isolated from suspected patient ear discharges with otitis media in Wollo area, the northeastern part of Ethiopia.

This ten-year retrospective analysis revealed that gender has no influence on the risk of acquiring middle ear infection. Likewise, most investigators have reported no clear gender based difference exists in the risk of acquiring middle ear infection $[23,27]$. However, we found that age has a strong association with the risk of acquiring middle ear infection. Similar to our finding other previously reported data from Ethiopia and many other countries also showed age has significant influence on the risk of acquiring middle ear infections [18, 27]. For example, children are highly vulnerable to frequent ear infection due to pathogenic bacteria colonization in the middle ear or upper respiratory tract $[12,19,28-30]$.

In this study, the main pathogenic bacterium associated with middle ear infection was Proteus spp. followed by $S$. aureus and Pseudomonas spp., respectively. Similarly, previously published articles from our study area and other parts of Ethiopia also reported Proteus spp. were the foremost bacteria associated with middle ear infection followed by the later ones [12-19]. Although it needs a further nationwide study, taking into account our study finding and others, it seems that Proteus spp. is the leading bacterial isolates associated with middle ear infection in Ethiopia. Conversely, several other published data pieces from Africa and elsewhere in the world reported Pseudomonas spp., mainly P. aeruginosa, is the primary pathogenic bacteria associated with middle ear infection [5, 31-37]. One possible explanation for this difference might be due to climate and geographical variations between Ethiopia and those countries. It is noteworthy that this study and many other previously reported data indicated $S$. aureus is the second common bacterial isolates that often associated with middle ear infection $[15,18,32,34,37]$.

Ear infection is among the most common illnesses that leads to overprescription of antibiotic use, one of the reasons for the emergence of antibiotic resistant pathogenic bacteria $[23,24]$. In light of this evidence, our study revealed that most of the isolated pathogenic bacteria have become resistant to all the easily available antibiotics. In general, ampicillin, ceftriaxone, amoxicillin, and tetracycline had shown the highest antibiotic resistance rates to all bacterial pathogens isolated from middle ear discharge, respectively. Correspondingly, tetracycline, ampicillin, ceftriaxone, and erythromycin were the most clinically used antibiotics that showed a higher resistance rate to Proteus spp., which is in line with earlier reports from Ethiopia, Nigeria, and Egypt [17, 18, 38, 39].
Likewise, amoxicillin and ampicillin showed higher resistance rates to $S$. aureus; similar high percentage of resistance was also reported from Ethiopia and elsewhere in the world $[5,17,18,40,41]$. Amoxicillin, TMP-SMX, and erythromycin also showed a high level of resistance to Pseudomonas spp.; these findings are consistent with other studies [1719, 42]. Among the total Proteus spp. and Pseudomonas spp. isolated during the ten-year period about $72.5 \%$ and $62.2 \%$ of the isolated bacteria have developed resistance to one and more antibiotics that were once in clinical use, respectively. Overall, more than half of the bacterial isolates of this study were characterized as multi-antibiotic-resistant pathogenic bacteria. The reason for this high degree of multiantibiotic resistance might be linked to indiscriminate use of antibiotics, including animal husbandry, self-medication, and poor infection prevention and control practices as indicated by the recent $\mathrm{WHO}$ antimicrobial resistance report and earlier studies $[10,19,43,44]$.

Furthermore, this study revealed multi-antibioticresistant pathogenic bacteria have become increasing threats of otitis media over the last decade in Wollo area, northeastern Ethiopia. By comparing the start and end of the study periods (2001-2 versus 2010-11), the overall resistance rate of all bacterial isolates to one and more of the antibiotics was increased nearly twofold. This finding is higher than studies reported from other African countries and elsewhere in the world $[45,46]$. This increasing trend of multiantibiotic resistance rate against middle ear bacterial pathogens such as Proteus spp. and Pseudomonas spp. calls for more careful attention empirical treatment of middle ear infections in the study area.

Interestingly, our study revealed almost all the isolated pathogenic bacteria were considerably susceptible to ciprofloxacin and gentamicin. Particularly, ciprofloxacin was shown to be highly effective for the three leading pathogenic bacteria associated with middle ear infection in this study: Proteus spp., S. aureus, and Pseudomonas spp. Likewise, with a slight variation several other authors have shown a similar high efficiency of ciprofloxacin against these bacterial species $[5,15,17,47-51]$. Thus, we propose that ciprofloxacin can be taken as a first-line optional treatment for middle ear infection in Wollo area, northeast Ethiopia, as it is available in oral, injection, and topical ear drops formulation [48, 51]. This suggestion holds true, since the current first-line treatment for both acute and chronic otitis media in Ethiopia is amoxicillin [52], which already showed a high resistance rate $(81.9 \%)$ for the majority of the bacterial isolates in this study and in other published data from different parts of Ethiopia [14-19, 53]. Moreover, empiric therapy is advocated when the antibiotic resistance level is $10 \%$ or less [54]; however, our finding revealed that the resistance level of most alternative antibiotic treatments for middle ear infection was more than $10 \%$. This implies most common antibiotics used in our study area are no longer appropriate for empiric management of otitis media.

As limitations, the result of this study may not completely represent all the antibiotics used in the clinical practice in the study area since only those who visited the health research laboratory were included in the study and a retrospective 
study incomplete record and illegible handwriting eliminated some culture results and antibiotics from the study.

\section{Conclusion}

This study revealed that age and the risk of acquiring middle ear infection are strongly associated and Proteus spp., $S$. aureus, and Pseudomonas spp. were the three predominant bacteria isolates from patient ear discharges suspected of otitis media. Almost all the isolated bacteria showed a considerable level of resistance to more than one antibiotic that are commonly used in primary health care centers; particularly, majority of isolated bacteria were found to be highly resistant to ampicillin, ceftriaxone, amoxicillin, and tetracycline treatments. More than two-thirds of Proteus spp. and Pseudomonas spp. have developed resistance to one and more antibiotics used to treat them. A comparative analysis of the overall antibiotic-resistance rate between the start and end of the study periods revealed that the rate of bacterial isolates resistant to one and more of the antibiotics was increased nearly twofold over the last decade in Wollo area, northeastern Ethiopia. This study also indicated ciprofloxacin and gentamicin are effective against all the bacterial isolates and most were highly sensitive to ciprofloxacin. In general, the result of this study revealed that antibiotic-resistant bacteria are alarmingly increasing in Wollo area, the northeastern part of Ethiopia, and becoming a major public health problem in the management patients with middle ear infection. Therefore, we strongly recommend nationwide antimicrobial surveillance to make the right recommendation of alternative antibiotics along with strict adherence to antibiotic policy to reduce the spread of drug resistant microbes in the country.

\section{Disclosure}

Asrat Agalu Abejew and Alemayehu Gashaw Mekonnen are coauthors.

\section{Conflict of Interests}

The authors declare that they have no competing interests.

\section{Authors' Contribution}

Ayele Argaw-Denboba and Asrat Agalu Abejew designed the study, collected the data and analysis and interpreted the data, and wrote and reviewed the initial and final drafts of the paper. Alemayehu Gashaw Mekonnen participated in the design of the study and data collection and reviewed the paper. All authors read and approved the final paper.

\section{Acknowledgments}

The authors would like to thank all staff members of Dessie Regional Health Research Laboratory. Their special thank is also given to Mr. Fekadu Biru, Head of Laboratory, for his timely help and encouragement during this work. Their deep gratitude also goes to Dr. Martino Miele for his linguistic assistance and editing the paper.

\section{References}

[1] A. Ullauri, A. Smith, M. Espinel, C. Jimenez, C. Salazar, and R. Castrillon, "WHO ear and hearing disorders survey: Ecuador national study 2008-2009," Conference Papers in Science, vol. 2014, Article ID 847526, 13 pages, 2014.

[2] World Health Organization, "Deafness and hearing loss," Fact Sheet 300, 2015, http://www.who.int/mediacentre/factsheets/ fs300/en/.

[3] P. W. Alberti, "The pathophysiology of the ear," in Occupational Exposure to Noise Evaluation, Prevention and Control, B. Goelzer, C. H. Hansen, and G. A. Sehrndt, Eds., pp. 63-78, World Health Organization (WHO), 2001.

[4] A. S. Fauci, D. L. Kasper, D. L. Longo et al., Harrison's Principles of Internal Medicine, McGraw-Hill, New York, NY, USA, 17th edition, 2008.

[5] O. A. Afolabi, A. G. Salaudeen, F. E. Ologe, C. Nwabuisi, and C. C. Nwawolo, "Pattern of bacterial isolates in the middle ear discharge of patients with chronic suppurative otitis media in a tertiary hospital in north central Nigeria," African Health Sciences, vol. 12, no. 3, pp. 362-368, 2012.

[6] European Centre for Disease Prevention and Control, Antimicrobial Resistance Surveillance in Europe 2013. Annual Report of the European Antimicrobial Resistance Surveillance Network (EARS-Net), ECDC, Stockholm, Sweden, 2014.

[7] S. Forgie, G. Zhanel, and J. Robinson, "Management of acute otitis media," Paediatrics \& Child Health, vol. 14, no. 7, pp. 457460, 2009.

[8] J. E. Tobih, S. S. Taiwo, O. A. Olowe, O. A. Olaosun, and S. D. Adejumo, "Clinical and microbiological profiles of ear infections in Osogbo, Nigeria," Tropical Doctor, vol. 36, no. 3, pp. 165-166, 2006.

[9] A. J. Sosa, D. K. Byarugaba, C. F. Amabile-Cuevas, P. R. Hsueh, S. Kariuki, and I. N. Okeke, Antimicrobial Resistance in Developing Countries, Springer, New York, NY, USA, 2010.

[10] World Health Organization, Antimicrobial Resistance: Global Report on Surveillance, World Health Organization, 2014.

[11] B. Edwin, V. Prasanna, I. Kannan, V. H. Katiyar, and E. Dhanapal, "Incidence of bacterial colonization in the oropharynx of patients with ear, nose and throat infections," International Journal of Medical Science and Public Health, vol. 3, no. 8, pp. 931-934, 2014.

[12] A. Melaku and S. Lulseged, "Chronic suppurative otitis media in children hospital in Addis Ababa, Ethiopia," Ethiopian Medical Journal, vol. 37, no. 4, pp. 237-246, 1999.

[13] D. Ferede, A. Geyid, S. Lulseged, and A. Melaku, "Drug susceptibility pattern of bacterial isolates from children with chronic suppurative otitis media," Ethiopian Journal of Health Development, vol. 15, no. 2, pp. 89-96, 2001.

[14] D. Muleta, S. Gebre-Selassie, and H. Nida, "Isolation and antimicrobial susceptibility patterns of bacterial pathogens causing otitis media in children in Jimma Hospital, Southwestern Ethiopia," Ethiopian Journal of Health Sciences, vol. 14, pp. 89-100, 2004.

[15] B. Abera and F. Biadeglegne, "Antimicrobial resistance patterns of Staphylococcus aureus and Proteus spp. Isolated from otitis media at Bahir Dar Regional Laboratory, North West Ethiopia," Ethiopian Medical Journal, vol. 47, no. 4, pp. 271-276, 2009.

[16] G. Tesfaye, D. Asrat, Y. Woldeamanuel, and M. Gizaw, "Microbiology of discharging ears in Ethiopia," Asian Pacific Journal of Tropical Medicine, vol. 2, no. 1, pp. 60-67, 2009. 
[17] B. Abera and M. Kibret, "Bacteriology and antimicrobial susceptibility of otitis media at dessie regional health research laboratory, Ethiopia," Ethiopian Journal of Health Development, vol. 25, no. 2, pp. 161-167, 2011.

[18] A. Seid, F. Deribe, K. Ali, and G. Kibru, "Bacterial otitis media in all age group of patients seen at Dessie referral hospital, North East Ethiopia," Egyptian Journal of Ear, Nose, Throat and Allied Sciences, vol. 14, no. 2, pp. 73-78, 2013.

[19] D. Muluye, Y. Wondimeneh, G. Ferede, F. Moges, and T. Nega, "Bacterial isolates and drug susceptibility patterns of ear discharge from patients with ear infection at Gondar University Hospital, Northwest Ethiopia," BMC Ear, Nose and Throat Disorders, vol. 13, no. 1, article 10, 2013.

[20] CSA, Population Projection of Ethiopia for all Regions at Woreda Level from 2014-2017, Central Statistical Agency, Addis Ababa, Ethiopia, 2013.

[21] M. Cheesbourgh, Medical Laboratory Manual for Tropical Countries. Part 2, Butterworthr-Heineman LTD, England, UK, 2nd edition, 2006.

[22] A. W. Bauer, W. M. Kirby, J. C. Sherris, and M. Turch, "Antibiotic susceptibility testing by a standardized single disk method," American Journal of Clinical Pathology, vol. 45, no. 4, pp. 493496, 1966.

[23] V. Yiengprugsawan and A. Hogan, "Ear infection and its associated risk factors, comorbidity, and health service use in Australian children," International Journal of Pediatrics, vol. 2013, Article ID 963132, 7 pages, 2013.

[24] C. Llor and L. Bjerrum, "Antimicrobial resistance: risk associated with antibiotic overuse and initiatives to reduce the problem," Therapeutic Advances in Drug Safety, vol. 5, no. 6, pp. 229-241, 2014.

[25] D. M. Livermore, "Current epidemiology and growing resistance of Gram-negative pathogens," The Korean Journal of Internal Medicine, vol. 27, no. 2, pp. 128-142, 2012.

[26] M. H. Kollef, "Broad-spectrum antimicrobials and the treatment of serious bacterial infections: getting it right up front," Clinical Infectious Diseases, vol. 47, supplement 1, pp. S3-S13, 2008.

[27] J. L. Paradise, H. E. Rockette, D. K. Colborn et al., "Otitis media in 2253 Pittsburgh-area infants: prevalence and risk factors during the first two years of life," Pediatrics, vol. 99, no. 3, pp. 318-333, 1997.

[28] R. Mittal, G. Robalino, R. Gerring et al., "Immunity genes and susceptibility to otitis media: a comprehensive review," Journal of Genetics and Genomics, vol. 41, no. 11, pp. 567-581, 2014.

[29] A. O. Lasisi, "The chronic discharging ear in the Sub Saharan Africa: need for improved management," The Internet Journal of Otorhinolaryngology, vol. 7, no. 2, 2008.

[30] T. Tapiainen, T. Kujala, M. Renko et al., "Effect of antimicrobial treatment of acute otitis media on the daily disappearance of middle ear effusion: a placebo-controlled trial," JAMA Pediatrics, vol. 168, no. 7, pp. 635-641, 2014.

[31] T. Mansoor, M. A. Musani, G. Khalid, and M. Kamal, "Pseudomonas aeruginosa in chronic suppurative otitis media: sensitivity spectrum against various antibiotics in Karachi," Journal of Ayub Medical College, Abbottabad, vol. 21, no. 2, pp. 120-123, 2009.

[32] F. Osazuwa, E. Osazuwa, C. Osime et al., "Etiologic agents of otitis media in Benin City, Nigeria," North American Journal of Medical Sciences, vol. 3, no. 2, pp. 95-98, 2011.
[33] M. J. Tanon-Anoh, A. Kacou-Ndouba, M. Yoda, E. Ette-Akre, D. Sanogo, and B. Kouassi, "Particularities of bacterial ecology of acute otitis media in an African subtropical country (Cote d'Ivoire)," International Journal of Pediatric Otorhinolaryngology, vol. 70, no. 5, pp. 817-822, 2006.

[34] E. Illing and O. Olaleye, "Malignant otitis externa: a review of aetiology, presentation, investigations and current management strategies," Otorhinolaryngology, vol. 2, no. 3, Article ID WMC001725, 2011.

[35] R. Bovo, A. Benatti, A. Ciorba, M. Libanore, M. Borrelli, and A. Martini, "Pseudomonas and Aspergillus interaction in malignant external otitis: risk of treatment failure," Acta Otorhinolaryngologica Italica, vol. 32, no. 6, pp. 416-419, 2012.

[36] P. H. Weckwerth, C. A. de Magalhães Lopes, M. A. H. Duarte et al., "Chronic suppurative otitis media in cleft palate: microorganism etiology and susceptibilities," The Cleft PalateCraniofacial Journal, vol. 46, no. 5, pp. 461-467, 2009.

[37] I. E. Alsaimary, A. M. Alabbasi, and J. M. Najim, "Antibiotics susceptibility of bacterial pathogens associated with otitis media," Journal of Bacteriology Research, vol. 2, no. 4, pp. 41-50, 2010.

[38] P. K. Feglo, S. Y. Gbedema, S. N. A. Quay, Y. Adu-Sarkodie, and C. Opoku-Okrah, "Occurrence, species distribution and antibiotic resistance of Proteus isolates: a case study at the Komfo Anokye Teaching Hospital (KATH) in Ghana," International Journal of Pharmaceutical Sciences and Research, vol. 1, no. 9, pp. 347-352, 2010.

[39] S. A. Bahashwan and H. M. El Shafey, "Antimicrobial resistance patterns of Proteus isolates from clinical specimens," European Scientific Journal, vol. 9, no. 27, 2013.

[40] M.-X. Zou, R.-R. Zhou, W.-J. Wu et al., "Antimicrobial resistance and molecular epidemiological characteristics of clinical isolates of Staphylococcus aureus in Changsha area," Chinese Medical Journal, vol. 125, no. 13, pp. 2289-2294, 2012.

[41] C. E. Udobi, A. F. Obajuluwa, and J. A. Onaolapo, "Prevalence and antibiotic resistance pattern of methicillin-resistant Staphylococcus aureus from an orthopaedic hospital in Nigeria," BioMed Research International, vol. 2013, Article ID 860467, 4 pages, 2013.

[42] E. S. Amadi, P. N. Uzoaru, I. Orji, A. A. Nwaziri, and I. R. Iroha, "Antibiotic resistance in clinical isolates of Pseudomonas aeruginosa in Enugu and Abakaliki, Nigeria," Internet Journal of Infectious Diseases, vol. 7, article 9474, 2009.

[43] A. A. Abejew, A. A. Denboba, and A. G. Mekonnen, "Prevalence and antibiotic resistance pattern of urinary tract bacterial infections in Dessie area, Northeast Ethiopia," BMC Research Notes, vol. 7, no. 1, article 687, 2014.

[44] K. S. O’Brien, S. Blumberg, W. T. A. Enanoria, S. Ackley, N. Sippl-Swezey, and T. M. Lietman, "Antibiotic use as a tragedy of the commons: a cross-sectional survey," Computational and Mathematical Methods in Medicine, vol. 2014, Article ID 837929, 8 pages, 2014.

[45] A. N. Kimang'a, "A situational analysis of antimicrobial drug resistance in Africa: are we losing the battle?" Ethiopian Journal of Health Sciences, vol. 22, no. 2, pp. 135-143, 2012.

[46] L. J. McGrath, S. Becker-Dreps, V. Pate, and M. A. Brookhart, "Trends in antibiotic treatment of acute otitis media and treatment failure in children, 2000-2011," PLoS ONE, vol. 8, no. 12, Article ID e81210, 2013.

[47] A. O. Ibekwe, Z. A. L. Shareef, and A. Benayam, "Anaerobes and fungi in chronic suppurative otitis media," Annals of Otology, Rhinology \& Laryngology, vol. 106, no. 8, pp. 649-652, 1997. 
[48] M. A. Aslam, Z. Ahmed, and R. Azim, "Microbiology and drug sensitivity patterns of chronic suppurative otitis media," Journal of the College of Physicians and Surgeons-Pakistan, vol. 14, no. 8, pp. 459-461, 2004.

[49] J. Kwiecińska-Piróg, K. Skowron, K. Zniszczol, and E. Gospodarek, "The assessment of Proteus mirabilis susceptibility to ceftazidime and ciprofloxacin and the impact of these antibiotics at subinhibitory concentrations on Proteus mirabilis biofilms," BioMed Research International, vol. 2013, Article ID 930876, 8 pages, 2013.

[50] R. Mösges, M. Nematian-Samani, and A. Eichel, “Treatment of acute otitis externa with ciprofloxacin otic $0.2 \%$ antibiotic ear solution," Therapeutics and Clinical Risk Management, vol. 7, pp. 325-336, 2011.

[51] G. S. Renukananda, U. P. Santosh, and N. M. George, “Topical vs combination ciprofloxacin in the management of discharging chronic suppurative otitis media," Journal of Clinical and Diagnostic Research, vol. 8, no. 6, pp. KC01-KC04, 2014.

[52] EFMHACA, Standard Treatment Guidelinesfor Primary Hospital, The Ethiopian Food, Medicine and Healthcare Administration and Control Authority (EFMHACA), Addis Ababa, Ethiopia, 3rd edition, 2014.

[53] S. Gebre-Sealsssie, "Antimicrobial resistance patterns of clinical bacterial isolates in southwestern Ethiopia," Ethiopian Medical Journal, vol. 45, no. 4, pp. 363-370, 2007.

[54] K. Gupta, T. M. Hooton, K. G. Naber et al., "International clinical practice guidelines for the treatment of acute uncomplicated cystitis and pyelonephritis in women: a 2010 update by the Infectious Diseases Society of America and the European Society for Microbiology and Infectious Diseases," Clinical Infectious Diseases, vol. 52, no. 5, pp. e103-e120, 2011. 

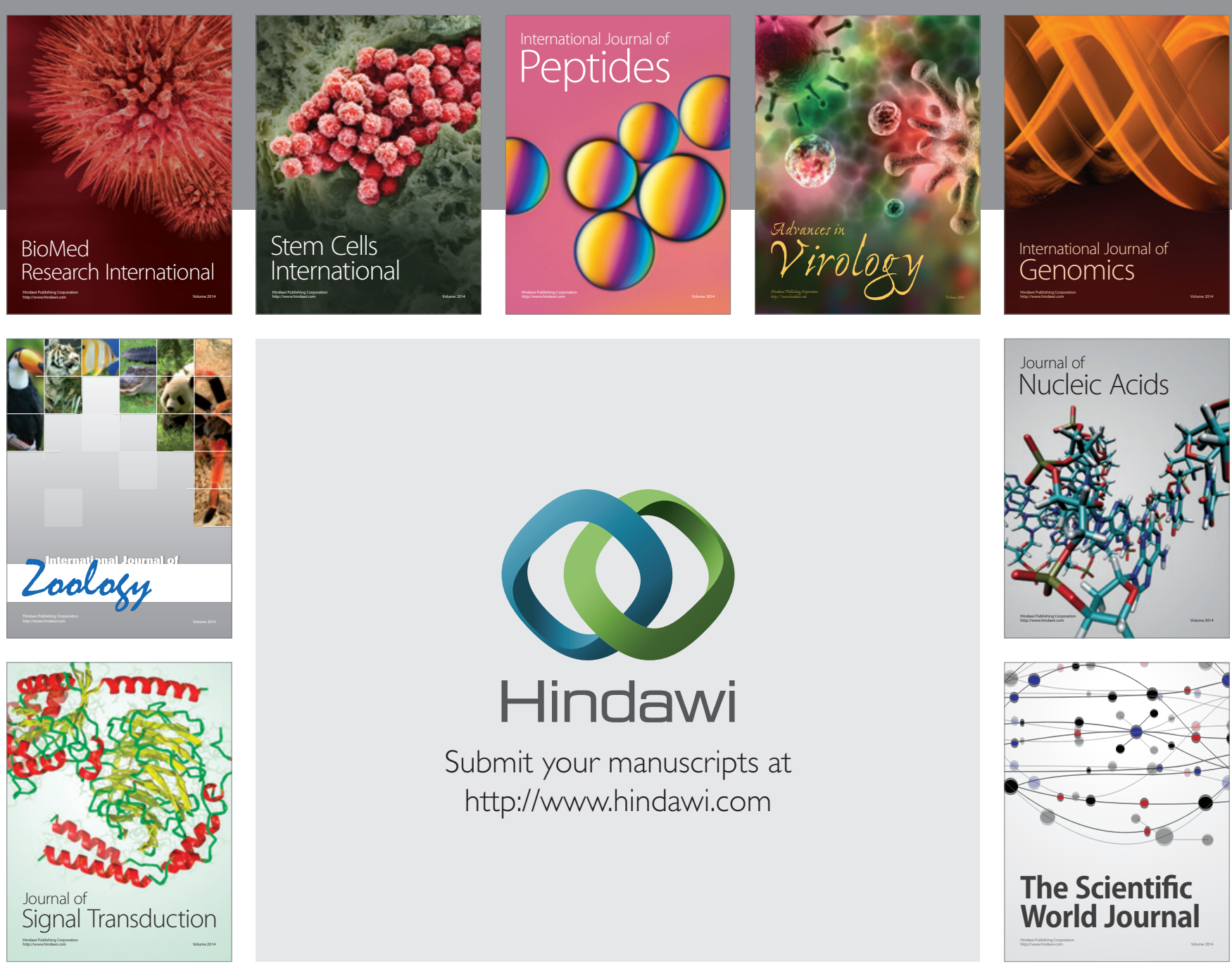

Submit your manuscripts at

http://www.hindawi.com
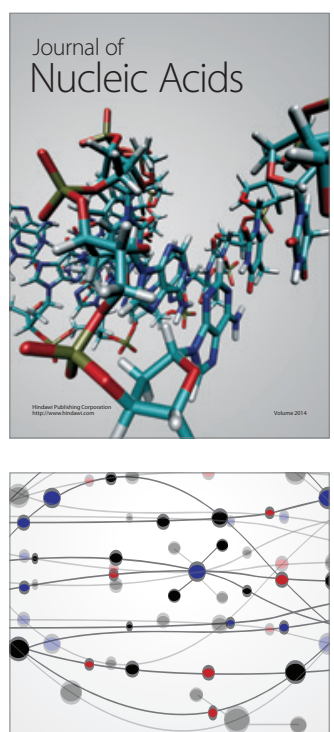

The Scientific World Journal
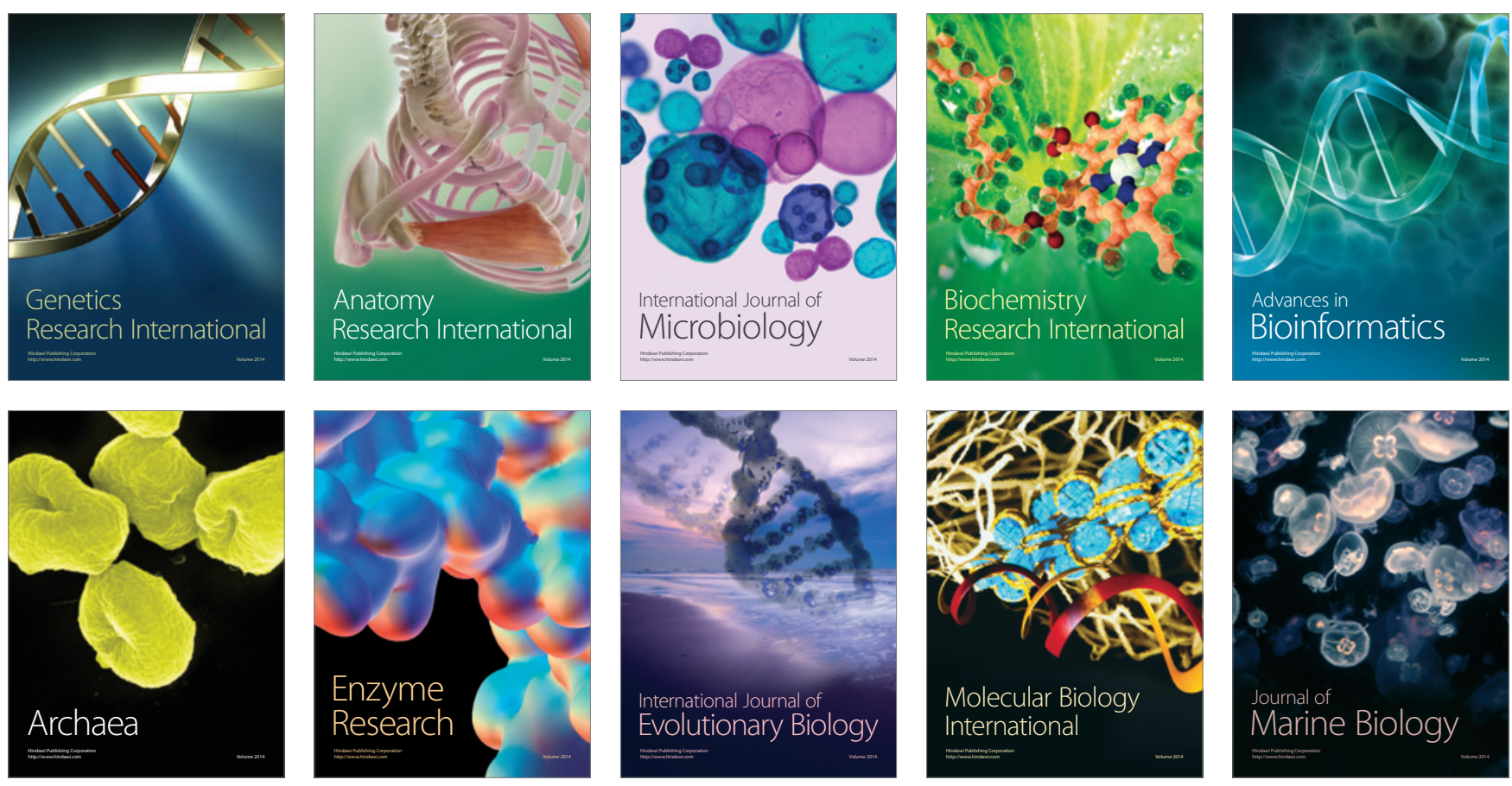